\title{
Parental Concerns Based General Developmental Screening Tool and Autism Risk: The Taiwan National Birth Cohort Study
}

\author{
FOR-WEY LUNG, BIH-CHING SHU, TUNG-LIANG CHIANG, AND SHIO-JEAN LIN
}

\begin{abstract}
Department of Medicine [F.-W.L.], Kaohsiung Armed Forces General Hospital, Kaohsiung 802, Taiwan; Graduate Institute of Behavioral Sciences [F.-W.L.], Kaohsiung Medical University, Kaohsiung 807, Taiwan; Department of Psychiatry [F.-W.L.], National Defense Medical Center, Taipei 114, Taiwan; Calo Psychiatric Center [F.-W.L.], Pingtung County 925, Taiwan; Institute of Allied Health Sciences and Departments of Nursing [B.-C.S.] and Pediatrics [S.-J.L.], National Cheng Kung University, Tainan 701, Taiwan; Institute of Health Policy and Management [T.-L.C.], National Taiwan University, Taipei 106, Taiwan
\end{abstract}

\begin{abstract}
Early detection of developmental delay and childhood disorders are important for early intervention. This study aimed to describe the distribution of responses in a large population-based survey, identify cutoff points for the parent concern checklist (PCC) suitable for the Chinese language and culture, and explore how many children were identified as having evidence of problems at age 18 mo different from those at age 6 mo. Using a national randomly selected sample, the overall development of 21,248 children was investigated using the Taiwan Birth Cohort study instrument, and the PCC, a problem-oriented screening instrument. The Newton-Raphson iteration showed that the PCC should be separated into three groups, those scoring 1-2 in the first group, 3-6 in the second group, and 7-8 in the third group. Structural equation models showed that 6-mo development was predictive of 18-mo development; additionally, 18-mo development and the PCC showed good concurrent validity. This study identified three groups with distinct developmental trajectories and two cutoff points of $2 / 3$ and $6 / 7$. Thus, the PCC can be used as a first-stage screening instrument in a two-stage window screening procedure. Further studies are needed to investigate the factors, which contribute to the differences among these groups; follow-up on the typical and atypical development of these children is necessary. (Pediatr Res 67: 226-231, 2010)
\end{abstract}

A utism spectrum disorders (ASD) have an estimated prevalence of 6.7 per 1000 (1). Although previously, children with ASD were not normally diagnosed until age 4 y or older, recent advances have facilitated the identification and diagnosis of these children at toddlerhood (2). Early diagnosis has enabled these children to attend early intervention sooner, which has been shown to be effective in decreasing autistic symptomology (3) and also decrease family stress (4). Glascoe and Dworkin (5) proposed that parental reports increased the accuracy of clinical judgments in detecting children with behavioral and developmental problems; this seems to be the most efficient developmental detection method for physicians to administer and interpret (6). For ASD, autism-specific screening tools, such as the modified checklist of autism in

Received April 27, 2009; accepted October 13, 2009.

Correspondence: Bih-Ching Shu, Sc.D., Institute of Allied Health Sciences and Department of Nursing, National Cheng Kung University, No. 1 Da-Hsueh Rd., Tainan, Taiwan 701; e-mail: forweylung@gmail.com; shubih@mail.ncku.edu.tw

The Taiwan Birth Cohort Study was funded by the Bureau of Health Promotion, Department of Health, Taiwan, R.O.C. (grants DOH93-HP-1702, DOH94-HP-1802, DOH95-HP-1802, DOH96-HP-1702). The views expressed herein are the authors' own. toddlers (M-CHAT) have been widely used in research and clinical settings (2); however, parents need to be aware of these children and bring these concerns to their pediatrician before the children can receive such screening. In addition, pediatricians sometimes fail to ask parents about their concerns, thus a broadband screening checklist can be helpful for pediatricians in understanding parental concerns.

Although some research suggests that ASD can be detected at 6 mo (7), another study showed that most parents reveal their concerns regarding their children's slow or uneven development in language and socialization at 18 mo (8). Similarly, other studies have shown that delayed language was the most frequently reported behavior at $18 \mathrm{mo}$, and some even noted a regression of language at 18 mo (9-11). Eighteen months can be a critical point for detection, because before or up to 6 mo, executive and activity dysregulation are normal due to the immaturity of the frontal lobe function (12), and these action schemata are better coordinated at about $1 \mathrm{y}$ of development age $(13,14)$. Thus, from 12 to 18 mo, children's cognitive functions are more mature, so it is easier for parents and physicians to detect their slow or uneven development.

To increase sensitivity, it has been suggested that surveillance and screening be included in every well-child preventive care visit (15). However, broadband screening has been criticized for its high rate of over referrals, which may lengthen the waiting list for treatment (16); therefore, after the first broadband screening, a more specific testing is needed (15). Chien et al. (17) proposed a more efficient two-stage window screening method, which can be used to reduce the aforementioned broadband screening limitation. In this screening method, two cutoff points are needed, yielding three groups: those in the first (highest scoring) group are normal (assuming higher scores are better); and those in the third (lowest) group have the highest risk for the disorder and can be directly assessed using diagnostic tools such as the autism diagnostic inventory—revised (ADI-R) (18); those in the middle group,

Abbreviations: ADI-R, autism diagnostic inventory—revised; ADOS, autism diagnostic observation schedule; AGFI, adjusted goodness-of-fit index; ASD, autism spectrum disorders; DD, developmental delays; M-CHAT, modified checklist of autism in toddlers; PCC, parent concern checklist; SEM, structural equation modeling; TBCS, Taiwan Birth Cohort study 
between the two cutoff points, have the highest probability of being misclassified and need to be further screened using a more specific screening instrument, such as the M-CHAT. A lower number of people need to be screened in the second stage using this method, which also decreases the cost of testing (17).

As mentioned earlier, broadband screening can be used to assist pediatricians in asking parents about their concerns. Previous studies that compared ASD-specific (e.g. M-CHAT) and broadband screening instruments [e.g. parents' evaluation of developmental status (PEDS)] have criticized broadband screening for its over referral (16) and failure to detect a portion of those with ASD (19). This problem can be solved by using the two-stage window screening method; however, to use this method, a large sample is needed to look at the distribution of these children to determine the two best cutoff points, so as to increase the positive predictive value. Also, to reduce over referral, Glascoe et al. (16) recommended that unique patterns of parental concerns should be noted. To detect these patterns, we would need to detect the differences in developmental distributions in a large-scale populationbased sample. Therefore, there were two purposes to this study: 1) to describe the distribution of responses in a large population-based survey and identify cutoff points for the parent concern checklist (PCC) suitable for the Chinese language and culture and 2) to investigate how many children identified as different at $18 \mathrm{mo}$ had evidence of problems at 6 mo, using a large sample.

\section{METHODS}

This study used the dataset from the Taiwan Birth Cohort study (TBCS). The TBCS is a large-scale national study on child development. Out of all infants born in 2005, 24,200 were selected using two-stage stratified random sampling. At the first stage of sampling, 85 cities and towns were systematically randomly selected out of the 369 cities and towns in Taiwan. At the second stage, proportional probability to the rate of birth (separated into 12 levels) was used to select newborns from the birth registers of these 85 cities. At 6 mo, 21,248 newborns and families (87.8\%) were visited by trained researchers, and the collection of both demographic and developmental information was completed. At $18 \mathrm{mo}$, these researchers revisited these families again, and 20,172 (94.94\%) agreed to participate in the follow-up. The study protocol was approved by the institutional review board of a teaching hospital in Taiwan, and informed consent was obtained from all participants at both stages of the study.

At $6 \mathrm{mo}$, parents were asked to fill out the TBCS instrument for 6-mo development, and at $18 \mathrm{mo}$, parents had to fill out the TBCS for $18 \mathrm{mo}$ and an additional PCC instrument. Both the PCC and TBCS are broadband screening instruments; however, the PCC is a problem-oriented instrument inquiring into parental concerns about their children's development, and the TBCS measures the overall development of children. Both instruments were used in this study to investigate the developmental distribution of children.

The PCC includes eight items with yes-no responses. Items from PEDS (20) were used as a reference for this checklist in combination with the structure of the TBCS developmental instrument (21). Different from the PEDS, there is no algorithm in the PCC; the scoring of the PCC only requires the addition of all the items. In line with the structure of the TBCS developmental instrument, the eight items can be separated into four dimensions of gross motor (1 item), fine motor (1 item), and language (2 items), and four items measuring social communication development. Higher total scores meant parents expressed more concerns, thus worse development.

There are 26 items in the TBCS 6-mo scale, and 17 in the 18-mo scale measuring the children's daily performance based on parental observations. The items were answered using a three-point Likert scale. Higher scores meant better development. The TBCS has shown good reliability and validity in Taiwan (21).
Statistical analysis. The demographic distribution of the infants and parents was analyzed using descriptive analysis. The internal consistency of the PCC was tested using the Spearman correlation. SPSS 15.0 for Windows (Chicago, IL) was used for the earlier analysis. The developmental distribution of the PCC was analyzed using the Newton-Raphson iteration on the computer program MIX (22), which decomposes the distribution of the dataset under the estimated and defined parameters of components. In addition, Newton-Raphson was also used to find the two best cutoff points for the PCC. ANOVA was used to investigate the differences between the groups using the cutoff points found using the Newton-Raphson iteration. Finally, the concurrent validity of the TBCS and PCC at 18 mo was analyzed using structural equation modeling (SEM) analysis in the AMOS 7.0 statistical software package (SPSS). SEM was also used to test whether 6-mo TBCS results can predict 18-mo PCC results. Alternative hypothesized null models were analyzed and modified to reach the final model with the best fit. SEM results are presented in terms of $\chi^{2}, p$ value, goodness-of-fit index, and adjusted goodness-of-fit index (AGFI). The significance of $\chi^{2}$ is judged by the $p$ value: a greater $p$ value implies that the model has a better fit. AGFI indicates the variance of the model: when AGFI is $>0.9$, the model exhibits a good fit; therefore, a model with a $p$ value $>0.5$ and AGFI $>0.9$ implies that the null model approximates the real structure.

\section{RESULTS}

The demographics of the infants and their parents are shown in Table 1. Of the 21,248 children, about half were male $(52.5 \%)$. The mean age of the fathers was $32.5 \pm 5.5 \mathrm{y}$ and the mothers, $28.9 \pm 4.9 \mathrm{y}$.

Correlation coefficients of gross motor, fine motor, language, and behavior were between 0.26 and 0.61 , all statistically significant. A previous study has shown that the ideal correlation between different dimensions is between 0.30 and 0.75 (21). A correlation $>0.30$ demonstrates that the dimensions are in synch with each other; however, a correlation $>0.70$ shows that the dimensions have bad discriminative validity. Thus, the PCC shows good synchronization and still maintains its discriminative ability.

The distribution of the PCC as shown on the NewtonRaphson iteration for these 21,248 children at 18 mo is shown in Table 2. The Newton-Raphson iteration shows that the PCC should be separated into three groups, those scoring 1-2 in the first group, 3-6 in the second group, and 7-8 in the third group, thus, yielding the two cutoff points of $3 / 4$ and 6/7.

The differences in the TBCS developmental results of these three groups were compared using ANOVA. There were 17,492 infants in the first group, 2,420 in the second, and 256

Table 1. The demographics of the children and their parents $(\mathrm{N}=21,248)$

\begin{tabular}{|c|c|c|}
\hline & & $n(\%)$ \\
\hline Boys & & $11145(52.5)$ \\
\hline \multicolumn{3}{|l|}{ Maternal education } \\
\hline Elementary school & & $846(4.0)$ \\
\hline Junior high & & $2301(10.8)$ \\
\hline High school & & $8498(40.0)$ \\
\hline University/college & & $8861(41.7)$ \\
\hline Graduate school & & $741(3.5)$ \\
\hline \multicolumn{3}{|l|}{ Paternal education } \\
\hline Elementary school & & 307 (1.4) \\
\hline Junior high & & $2631(12.4)$ \\
\hline High school & & $8460(39.8)$ \\
\hline University/college & & $8236(38.8)$ \\
\hline \multirow[t]{2}{*}{ Graduate school } & & $1614(7.6)$ \\
\hline & Mean (SD) & Range \\
\hline Paternal age & $32.8(5.5)$ & $17-79$ \\
\hline Maternal age & $28.9(4.9)$ & $14-48$ \\
\hline
\end{tabular}


Table 2. The Newton-Raphson iteration on the distribution of the PCC

\begin{tabular}{cccc}
\hline & \multicolumn{3}{c}{$p$} \\
\cline { 2 - 4 } PCC score & Group 1 & Group 2 & Group 3 \\
\hline 1 & 85.08 & 14.92 & 0.00 \\
2 & 73.29 & 26.71 & 0.00 \\
3 & 48.58 & 51.42 & 0.00 \\
4 & 18.84 & 81.15 & 0.01 \\
5 & 3.88 & 95.61 & 0.51 \\
6 & 0.43 & 84.99 & 14.58 \\
7 & 0.01 & 26.89 & 73.10 \\
8 & 0.00 & 0.03 & 96.97 \\
\hline
\end{tabular}

in the third group. There were statistically significant differences between all groups in the TBCS developmental dimensions, with effect sizes ranging from 0.13 to 1.18 , as shown in Table 3. At 6 mo, the effect sizes were inconsistent among the four dimensions, and there was a large effect size (1.18) in the dimension of fine motor. At $18 \mathrm{mo}$, the effect size of the four dimensions was synchronistic (around 0.6).

Using the PCC cutoff points for analysis, with the means of mixture analysis, the prevalence of developmental delays (DD) at 18 mo was $13.4 \%$ (12.2\% mild DD and $1.2 \%$ moderate DD), as shown in Figure 1. There were significant differences in the PCC measure using the TBCS developmental instruments at 6 and 18 mo (Table 3). Especially, the PCC seemed also to have good discriminative ability in the four dimensions of gross motor, fine motor, language, and social development at $6 \mathrm{mo}$ and to suggest a probable screening method before 18 mo.

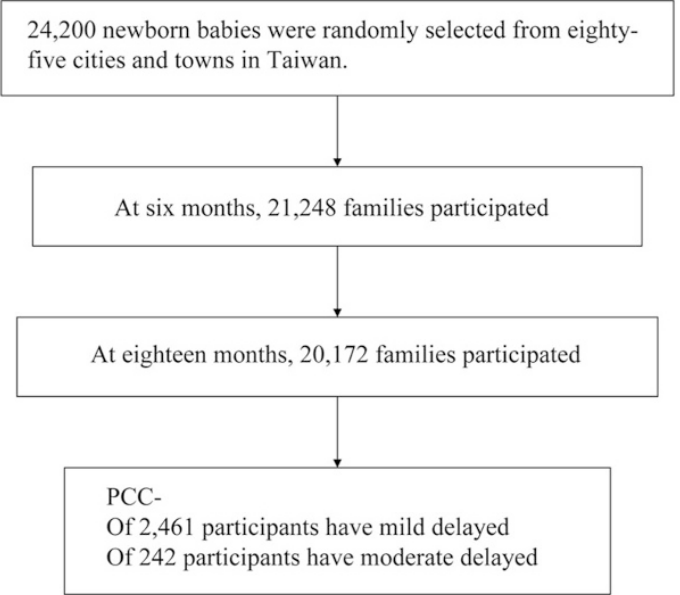

Figure 1. Overview of the participation rate. TBCS, Taiwan Birth Cohort study instrument; PCC, parent concern checklist. At 6 mo, there was $87.8 \%$ response rate. At $18 \mathrm{mo}$, there was $94.9 \%$ response rate. Of 2461 participants have mild delayed (12.2\%). Of 242 participants have moderate delayed $(1.2 \%)$.

SEM analysis was used to test the concurrent validity of the TBCS and PCC results at 18 mo. In addition, the sample was separated based on the three groups suggested by the NewtonRaphson analysis: the first group with the lowest scores on the PCC was composed of those presumed to be normal (with the least number of concerns). Results showed that 6-mo TBCS was predictive of 18-mo results; in addition, 18-mo TBCS and PCC showed good concurrent validity with each other in both the second group and the third group, as shown in Figure 2.

Table 3. The developmental differences in the three parent concern groups measured using Taiwan Birth Cohort study developmental instruments at 6 and 18 mo

\begin{tabular}{|c|c|c|c|c|c|c|}
\hline TBCS dimensions & $\begin{array}{c}\text { Group } 1 n=17,492 \\
\text { mean }(\mathrm{SD})\end{array}$ & $\begin{array}{c}\text { Group } 2 n=2420 \\
\text { mean }(\mathrm{SD})\end{array}$ & $\begin{array}{c}\text { Group } 3 n=256 \\
\text { mean }(\mathrm{SD})\end{array}$ & ANOVA & Tukey's posthoc test & Cohen's $d$ \\
\hline \multicolumn{7}{|l|}{$6 \mathrm{mo}$} \\
\hline \multirow[t]{3}{*}{ Gross motor } & $22.93(3.36)$ & $22.47(3.46)$ & $21.77(4.35)$ & $F=32.78$ & $\mathrm{G} 1>\mathrm{G} 2, \mathrm{MD}=0.46, p<0.001$ & 0.13 \\
\hline & & & & $p<0.001$ & $\mathrm{G} 1>\mathrm{G} 3, \mathrm{MD}=1.16, p<0.001$ & 0.30 \\
\hline & & & & & $\mathrm{G} 2>\mathrm{G} 3, \mathrm{MD}=0.71, p<0.001$ & 0.18 \\
\hline \multirow[t]{3}{*}{ Fine motor } & $16.65(1.90)$ & $16.39(2.11)$ & $13.96(2.62)$ & $F=32.36$ & $\mathrm{G} 1>\mathrm{G} 2, \mathrm{MD}=0.25, p<0.001$ & 0.13 \\
\hline & & & & $p<0.001$ & $\mathrm{G} 1>\mathrm{G} 3, \mathrm{MD}=0.68, p<0.001$ & 1.18 \\
\hline & & & & & $\mathrm{G} 2>\mathrm{G} 3, \mathrm{MD}=0.43, p<0.001$ & 1.02 \\
\hline \multirow[t]{3}{*}{ Language } & $21.18(2.45)$ & $20.83(2.58)$ & $20.57(2.88)$ & $F=27.11$ & $\mathrm{G} 1>\mathrm{G} 2, \mathrm{MD}=0.34, p<0.001$ & 0.14 \\
\hline & & & & $p<0.001$ & $\mathrm{G} 1>\mathrm{G} 3, \mathrm{MD}=0.60, p<0.001$ & 0.23 \\
\hline & & & & & $\mathrm{G} 2>\mathrm{G} 3, \mathrm{MD}=0.25, p<0.001$ & 0.10 \\
\hline \multirow[t]{3}{*}{ Social } & $6.09(1.62)$ & $5.97(1.65)$ & $5.71(1.68)$ & $F=12.99$ & $\mathrm{G} 1>\mathrm{G} 2, \mathrm{MD}=0.13, p<0.001$ & 0.07 \\
\hline & & & & $p<0.001$ & $\mathrm{G} 1>\mathrm{G} 3, \mathrm{MD}=0.38, p<0.001$ & 0.23 \\
\hline & & & & & $\mathrm{G} 2>\mathrm{G} 3, \mathrm{MD}=0.25, p<0.001$ & 0.16 \\
\hline \multicolumn{7}{|l|}{$18 \mathrm{mo}$} \\
\hline \multirow[t]{3}{*}{ Gross motor } & $14.06(1.39)$ & $13.54(1.81)$ & $12.70(2.93)$ & $F=228.58$ & $\mathrm{G} 1>\mathrm{G} 2, \mathrm{MD}=0.52, p<0.001$ & 0.32 \\
\hline & & & & $p<0.001$ & $\mathrm{G} 1>\mathrm{G} 3, \mathrm{MD}=1.36, p<0.001$ & 0.59 \\
\hline & & & & & $\mathrm{G} 2>\mathrm{G} 3, \mathrm{MD}=0.84, p<0.001$ & 0.34 \\
\hline \multirow[t]{3}{*}{ Fine motor } & $8.11(1.26)$ & $7.70(1.50)$ & $7.20(2.02)$ & $F=155.02$ & $\mathrm{G} 1>\mathrm{G} 2, \mathrm{MD}=0.40, p<0.001$ & 0.29 \\
\hline & & & & $p<0.001$ & $\mathrm{G} 1>\mathrm{G} 3, \mathrm{MD}=0.91, p<0.001$ & 0.53 \\
\hline & & & & & $\mathrm{G} 2>\mathrm{G} 3, \mathrm{MD}=0.51, p<0.001$ & 0.28 \\
\hline \multirow[t]{3}{*}{ Language } & $10.17(2.12)$ & $9.26(2.38)$ & $8.70(2.70)$ & $F=237.79$ & $\mathrm{G} 1>\mathrm{G} 2, \mathrm{MD}=0.91, p<0.001$ & 0.40 \\
\hline & & & & $p<0.001$ & $\mathrm{G} 1>\mathrm{G} 3, \mathrm{MD}=1.46, p<0.001$ & 0.61 \\
\hline & & & & & $\mathrm{G} 2>\mathrm{G} 3, \mathrm{MD}=0.55, p<0.001$ & 0.22 \\
\hline \multirow[t]{3}{*}{ Social } & $13.29(1.70)$ & $12.59(1.98)$ & $12.00(2.91)$ & $F=227.50$ & $\mathrm{G} 1>\mathrm{G} 2, \mathrm{MD}=0.70, p<0.001$ & 0.38 \\
\hline & & & & $p<0.001$ & $\mathrm{G} 1>\mathrm{G} 3, \mathrm{MD}=1.29, p<0.001$ & 0.54 \\
\hline & & & & & $\mathrm{G} 2>\mathrm{G} 3, \mathrm{MD}=0.59, p<0.001$ & 0.24 \\
\hline
\end{tabular}




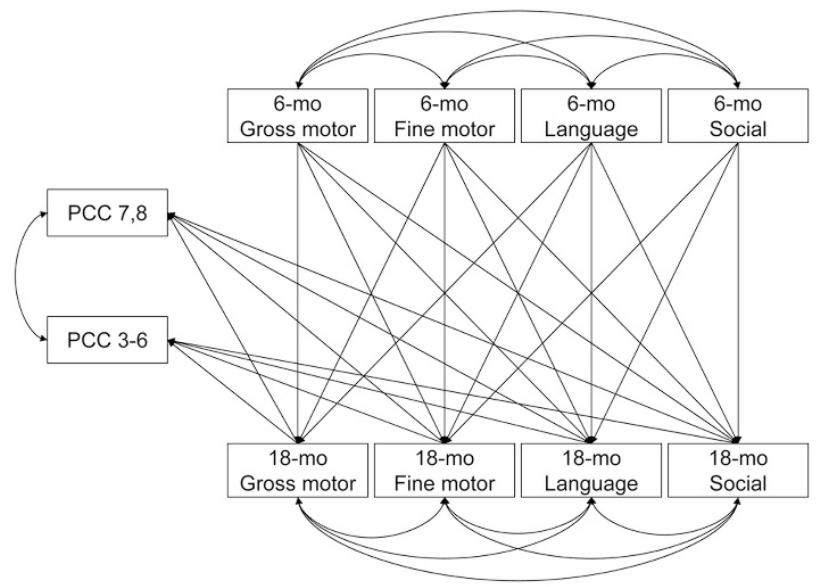

Figure 2. Structural equation model of concurrent validity between TBCS and PCC 18-mo results. $\chi^{2}=5.519$; df $=9 ; p=0.787$; AGFI $=1.000$. Group 2 PCC results (PCC 3-6): gross motor: $\beta=-0.05, p<0.001$; fine motor: $\beta=-0.03, p<0.001$; language: $\beta=-0.08, p<0.001$; social: $\beta=$ $-0.05, p<0.001$. Group 3 PCC results (PCC 7,8): gross motor: $\beta=-0.07$, $p<0.001$; fine motor: $\beta=-0.03, p<0.001$; language: $\beta=-0.03, p<$ 0.001 ; social: $\beta=-0.02, p<0.001$. r value: PCC 7,8 $\times$ PCC 3-6 $=-0.06$; 6 -mo gross motor $\times 6$-mo fine motor $=0.43$; 6-mo gross motor $\times 6$-mo language $=0.41 ; 6$-mo gross motor $\times 6$-mo social $=0.34 ; 6$-mo fine motor $\times$ 6-mo language $=0.47$; 6-mo fine motor $\times 6$-mo social $=0.41 ; 6$-mo language $\times 6$-mo social $=0.56 ; 18$-mo gross motor $\times 18$-mo fine motor $=$ 0.38 ; 18 -mo gross motor $\times 18$-mo language $=0.22 ; 18$-mo gross motor $\times$ 18 -mo social $=0.36 ; 18$-mo fine motor $\times 18$-mo language $=0.25 ; 18-\mathrm{mo}$ fine motor $\times 18$-mo social $=0.36$; 18 -mo language $\times 18$-mo social $=0.41$.

The concurrent validity between the TBCS at 18 mo and the PCC in groups 2 and 3 resulted in a $p$ value of 0.787 and AGFI of 1.000, as shown in Figure 2. All four dimensions of the TBCS (gross motor, fine motor, language, and social) were concurrent with the group 2 PCC results (gross motor: $\beta=$ $-0.05, p<0.001$; fine motor: $\beta=-0.03, p<0.001$; language: $\beta=-0.08, p<0.001$; social: $\beta=-0.05, p<$ $0.001)$. Along the same line, the concurrent validity between the TBCS at 18 mo and the PCC in group 3 also showed that all four dimensions of the TBCS were concurrent with the PCC results (gross motor: $\beta=-0.07, p<0.001$; fine motor: $\beta=-.03, p<0.001$; language: $\beta=-0.03, p<0.001$; social: $\beta=-0.02, p<0.001$ ).

The predictive validity of the TBCS 6-mo results for the PCC 18-mo results showed a good fit, with a $p$ value of 0.637 and AGFI of 1.000 for groups 2 and 3, as shown in Figure 3. TBCS results at 6 mo were predictive of parental concern for gross motor, fine motor, and language development at $18 \mathrm{mo}$ in the second group (gross motor: $\beta=-0.02, p=0.005$; fine motor: $\beta=-0.01, p=0.027$; language: $\beta=-0.03, p=$ $0.001)$ and gross and fine motor development in the third group (gross motor: $\beta=-0.02, p=0.001$; fine motor: $\beta=$ $-0.03, p<0.001)$.

\section{DISCUSSION}

Our results showed that the PCC had good internal consistency and discriminative ability in the four dimensions of gross motor, fine motor, language, and social development. In addition, it had good concurrent validity with the TBCS

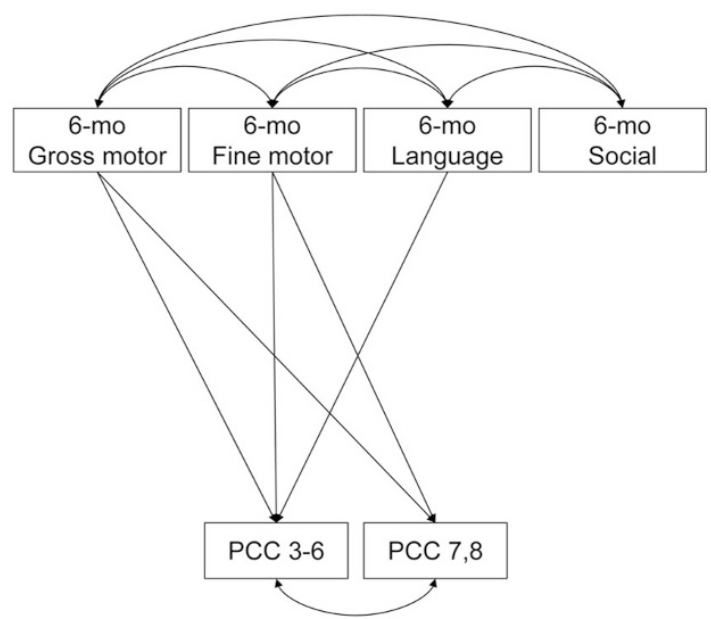

Figure 3. Structural equation model of predictive validity between 6-mo TBCS and 18-mo PCC results in $(A)$ those scoring 3-6 in the PCC and $(B)$ those scoring 7 and 8 in the PCC. $\chi^{2}=1.701$; $\mathrm{df}=3 ; p=0.637$; AGFI $=$ 1.000. r value: PCC 7,8 $\times$ PCC $3-6=-0.04 ; 6$-mo gross motor $\times 6$-mo fine motor $=0.43 ; 6$-mo gross motor $\times 6$-mo language $=0.41 ; 6$-mo gross motor $\times 6$-mo social $=0.34 ; 6$-mo fine motor $\times 6$-mo language $=0.47 ; 6-\mathrm{mo}$ fine motor $\times 6$-mo social $=0.41 ; 6$-mo language $\times 6$-mo social $=0.56$. TBCS results at 6 mo were predictive of parental concern for gross motor, fine motor, and language development at $18 \mathrm{mo}$ in the second group (PCC 3-6): gross motor: $\beta=-0.02, p=0.005$; fine motor: $\beta=-0.02, p=0.027$; language: $\beta=-0.03, p=0.001$. Gross and fine motor development in the third group (PCC 7,8): gross motor: $\beta=-0.02, p=0.001$; fine motor: $\beta=$ $-0.03, p<0.001$.

developmental instrument at 18 mo. For using two-stage window screening, the two cutoff points of $2 / 3$ and $6 / 7$ were found. The results from the posthoc comparisons indicated that the three groups showed statistically significantly different developmental distributions.

The TBCS 6-mo results were predictive of PCC 18-mo results in gross motor and fine motor development in the second group and gross motor, fine motor, and language development in the third group. Social development was not predicted in either the second or the third group. However, it has been shown that social development is a vital factor in distinguishing ASD from other DD (23). Specifically, a previous study found that children with ASD can be distinguished from other children with DD in their ability to respond to names, followed by pointing, face "reading" and functional play (24). But at $6 \mathrm{mo}$, children have greater development in the motor dimensions. Another study found that 6-mo motor development was predictive of the overall development of children at 18 mo (21). This may explain why at 6 mo, TBCS results could not predict 18-mo PCC results. The instability of the development of children before $1 \mathrm{y}$ of age can also explain why the stability of ASD diagnosis is better at $2 \mathrm{y}$ of age (25). On the other hand, the effect size $(<0.3)$ showed a similar finding of a lack of discriminating validity in the gross motor, language, and social dimensions. In addition, the effect size of fine motor $(>1.0)$ may be considered for further study.

Of interest, the TBCS language dimension at 6 mo was predictive of 18-mo PCC results in the second group, but not in the third. Language, especially communication, is another diagnostic criterion for ASD. A previous study found that 


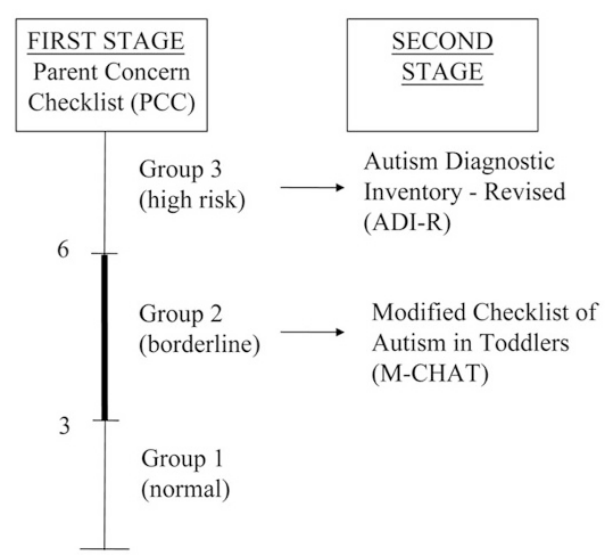

Figure 4. The two-stage window screening for autistic spectrum disorder using PCC as the first-stage screening instrument.

ASD children had greater impairment in receptive language and functional communication than those with language impairment (26). In addition, another study found that ASD children performed globally younger than other DDs (23); therefore, it may be possible that the differences distinguishing those in the second and third groups are the ASD and other DDs.

Although we are unsure of the cause of the differences among these three groups, we are sure that these groups do perform statistically significantly different in all dimensions of their development at 6 and 18 mo. Thus, the PCC can be used as the first-stage screening instrument in a two-stage window screening procedure. The American Academy of Pediatrics has proposed that developmental surveillance using developmental screening tools be incorporated into every well-child's visit (15). Herein, we propose an algorithm, which incorporates the use of two-stage window screening (17). Because the PCC has only eight items, it can easily be administered to parents in clinics or during home visits and be administered by professional or nonprofessional health workers. Parents can be given the PCC in the waiting rooms or asked by the pediatricians or nurses at every visit. The scoring of the PCC only requires the counting of the number of items that the parents are concerned, thus the person administering the screening can immediately judge, which developmental group the child falls into. As shown in Figure 4, once the person administering the screening calculates the score and decides, which group the child falls into, he/she will know if the child needs further testing. Those in the borderline group (group 2) should be administered another more specific screening instrument (such as the M-CHAT) to decide if they need a more invasive test; those in the third group are already at high risk, and so should directly receive a more invasive and detailed diagnostic assessment, such as the ADI-R (18) or the autism diagnostic observation schedule (ADOS) (3). The ADI-R and ADOS are both semistructured diagnostic assessments, which require intensive training on the part of the administrator; administration time generally requires $40 \mathrm{~min}$ for the ADOS and 2-3 h for the ADI-R $(3,18)$. In the traditional method of two-stage screening, all those scoring higher than the cutoff point need to be tested at the second stage, using a more invasive and expensive assessment (in this case, the ADOS or ADI-R) (6). However, using two-stage window screening, fewer people need to be assessed in the second stage, which decreases the cost of testing (17) and the number of false positives.

Frankenburg (27) proposed that a developmental screening tool include the four criteria of a precise developmental norm, predictive validity, identification of children at risk, and validity. The PCC fulfills all four of these criteria. Our developmental norm has been developed in a large national randomized sample, with the two cutoff points of $3 / 4$ and 6/7 identifying those at borderline and high risk, and finally, it has predictive validity with 6-mo TBCS results and concurrent validity with 18 -mo TBCS results.

A limitation of this study is that we did not know the differences between these three groups of children, what factors contributed to their differences, or whether they were children with different diagnoses. However, the results of our study are from the follow-up of a large randomized national sample. Therefore, there are no recalled biases in the reporting of earlier development. Furthermore, to find out whether the PCC can be used as a valid screening tool for ASD, a case-cohort study design or nested case-control study for this purpose will need to be implemented (28). This National Birth Cohort Study, that as designing is requirement for the understanding the prevalence of psychiatric disorder and comorbidity, and further identifying the developmental psychopathology in the future.

Acknowledgments. This study has relied on the work of many colleagues. We also thank the families who have given us generous cooperation at all stages of the study.

\section{REFERENCES}

1. Autism and Developmental Disabilities Monitoring Network Surveillance Year 2000 Principal Investigators; Centers for Disease Control and Prevention 2007 Prevalence of autism spectrum disorders-autism and developmental disabilities monitoring network, six sites, United States, 2000. MMWR Surveill Summ 56:1-11

2. Robins DL, Fein D, Barton ML, Green JA 2001 The modified checklist for autism in toddlers: an initial study investigating the early detection of autism and pervasive developmental disorders. J Autism Dev Disord 31:131-144

3. Lord C 2000 Commentary: achievements and future directions for intervention research in communication and autism spectrum disorders. J Autism Dev Disord 30:393-398

4. Scahill L 2005 Diagnosis and evaluation of pervasive developmental disorders. J Clin Psychiatry 66:19-25

5. Glascoe FP, Dworkin PH 1995 The role of parents in the detection of developmental and behavioral problems. Pediatrics 95:829-836

6. Glascoe FP, Foster EM, Wolraich ML 1997 An economic analysis of developmental detection methods. Pediatrics 99:830-837

7. Gillberg C, Nordin V, Ehlers S 1996 Early detection of autism. Diagnostic instruments for clinicians. Eur Child Adolesc Psychiatry 5:67-74

8. Siegel B, Pliner C, Eschler J, Elliott GR 1988 How children with autism are diagnosed: difficulties in identification of children with multiple developmental delays. J Dev Behav Pediatr 9:199-204

9. Bernabei P, Camaioni L 2001 Developmental profile and regression in a child with autism: a single case study. Autism 5:287-297

10. Davidovitch M, Glick L, Holtzman G, Tirosh E, Safir MP 2000 Developmental regression in autism: maternal perception. J Autism Dev Disord 30:113-119

11. DeMyer MK, Hingtgen JN, Jackson RK 1981 Infantile autism reviewed: a decade of research. Schizophr Bull 7:388-451

12. Zilbovicius M, Garreau B, Samson Y, Remy P, Barthélémy C, Syrota A, Lelord G 1995 Delayed maturation of the frontal cortex in childhood autism. Am J Psychiatry 152:248-252

13. Piaget J 1977 The Grasp of Consciousness. Routledge and Kegan Paul, London

14. Adrien JL, Rossignol-Deletang N, Martineau J, Couturier G, Barthelemy C 2001 Regulation of cognitive activity and early communication development in young autistic, mentally retarded, and young normal children. Dev Psychobiol 39:124-136

15. Council on Children with Disabilities, Section on Developmental Behavioral Pediatrics; Bright Futures Steering Committee and Medical Home Initiatives for Children 
with Special Needs Project Advisory Committee 2006 Identifying infants and young children with developmental disorders in the medical home: an algorithm for developmental surveillance and screening. Pediatrics 118:405-420

16. Glascoe FP, Macias MM, Wegner LM, Robertshaw NS 2007 Can a broadband developmental-behavioral screening test identify children likely to have autism spectrum disorder? Clin Pediatr (Phila) 46:801-805

17. Chien CC, Huang SF, Lung FW 2009 Maximally efficient two-stage screening: determining intellectual disability in Taiwanese military conscripts. J Multidiscip Healthc 2:39-44

18. Le Couteur A, Lord C, Rutter M 2003 The Autistic Diagnostic Interview-Revised (ADI-R). Western Psychological Services, Los Angeles

19. Pinto-Martin JA, Young LM, Mandell DS, Poghosyan L, Giarelli E, Levy SE 2008 Screening strategies for autism spectrum disorders in pediatric primary care. J Dev Behav Pediatr 29:345-350

20. Glascoe FP 2006 Parents' Evaluations of Developmental Status: A Method for Detecting and Addressing Developmental and Behavioral Problems in Children. Ellsworth \& Vandermeer Press, Nashville, TN

21. Lung FW, Shu BC, Chiang TL, Lin SJ 2008 Efficient developmental screening instrument for 6- and 18-month-old children in the Taiwan Birth Cohort Pilot Study. Acta Paediatr 97:1093-1098
22. Macdonald PD, Pitcher TJ 1979 Age-groups form size-frequency data: a versatile and efficient method of analyzing distribution mixtures. J Fish Res Board Can 36:987-1001

23. Ventola P, Kleinman J, Pandey J, Wilson L, Esser E, Boorstein H, Dumont-Mathieu T, Marshia G, Barton M, Hodgson S, Green J, Volkmar F, Chawarska K, Babitz T, Robins D, Fein D 2007 Differentiating between autism spectrum disorders and other developmental disabilities in children who failed a screening instrument for ASD. J Autism Dev Disord 37:425-436

24. Trillingsgaard A, Ulsted Sørensen E, Nemec G, Jørgensen M 2005 What distinguishes autism spectrum disorders from other developmental disorders before the age of four years? Eur Child Adolesc Psychiatry 14:65-72

25. Stone WL, Lee EB, Ashford L, Brissie J, Hepburn SL, Coonrod EE, Weiss BH 1999 Can autism be diagnosed accurately in children under 3 years? J Child Psychol Psychiatry 40:219-226

26. Loucas T, Charman T, Pickles A, Simonoff E, Chandler S, Meldrum D, Baird G 2008 Autistic symptomatology and language ability in autism spectrum disorder and specific language impairment. J Child Psychol Psychiatry 49:1184-1192

27. Frankenburg WK 1994 Preventing developmental delays: is developmental screening sufficient? Pediatrics 93:586-593

28. Gordis L 2009 Epidemiology. 4th ed. Elsevier Inc., Philadelphia, PA 